puzzle, though whether it has been inserted in the correct place remains to be seen. There occur a number of perplexing difficulties which the authors do not set out. Thus, although they do not find as great a proportion of bivalents as Jenkins in the pollen mother-cells in their undoubled $F_{1}$, it is still high. This, together with the report of seven perfectly normal bivalents and fairly regular tetrad formation in the hybrid Aegilops speltoides $\times T$. monococcum (Chizaki, 1932) and the 6-7 bivalents reported by Lilienfeld and Kihara (1934), as usually occurring in the hybrid $A$. speltoides $\times T$. Timopheevi $(A A G G)$, are difficult to reconcile with the assumption that $A$. speltoides contains the $C$ sets of chromosomes. Again, the authors make no mention of the number of nucleoli in their new wheat. In both $A$. speltoides and the emmer wheats there are four nucleoli (Pathak, 1940), so that the resulting amphidiploid will prob. ably have 8 nucleoli, whereas true vulgare wheats have only 6 . It may well be that the new type in reality has the constitution $A A B B A^{\prime} A^{\prime}$ rather than the elusive $A A B B C C$.

B. C. S.

\section{ROOTS OF MOUNTAINS}

DROF. BENO GUTENBERG, of Pasadena, California, has been doing a considerable amount of work recently on problems connected with the earth's crust immediately beneath high mountains. $\mathrm{He}$ has investigated in great detail the structure of Southern California as it may be interpreted in the light of data from 'near' earthquakes. In a recent paper he summarizes our present knowledge (much of which is due to himself) concerning the roots of mountains throughout the world ("Seismological Evidence for Roots of Mountains", by Beno Gutenberg. Bull. Geol. Soc. Amer., 54, 473-498; April 1, 1943).

Prof. Gutenberg states that all results based on the study of seismograms of nearby continental earthquakes indicate that below the sediments is a layer in which the velocity for longitudinal waves is between 5.55 and $5.60 \mathrm{~km}$./sec. It is considered granitic. Below it, intermediate layers showing higher velocities definitely show regional differences. Their lower boundary is the Mohorovičić discontinuity, below which a material, probably ultra-basic, in which the velocity is about $8.0 \mathrm{~km}$. $/ \mathrm{sec}$., is found nearly everywhere. The velocities through the granitic as well as those through the ultra-basic layers are the same in different regions, within $\pm 0.4 \mathrm{~km}$. $/ \mathrm{sec}$.

The maximum thickness $(60-70 \mathrm{~km}$.) of the 'continental layers' above the Mohorovičic discontinuity thus far has been found under the southern Alps and about the same under the Sierra Nevada. Whereas the root of the Alps seems to be due mainly to an increase in the thickness of the granitic layer, present indications are that the granitic layer under the Sierra Nevada extends roughly down to the same depth (about $20 \mathrm{~km}$.) as generally in Southern California; mainly the intermediate layers are thicker under the Sierra, In other continental regions, the Mohorovičić discontinuity is in general at a depth of about $50 \mathrm{~km}$. under areas with moderately high mountains, and of about $40 \mathrm{~km}$. near oceanic coasts. An especially low value of $30 \mathrm{~km}$. has been found in New Zealand. Under the Atlantic and Indian Oceans these layers have probably an even smaller total thickness and are practically absent under the Pacific Basin. The boundary of the crystalline crust is within the ultre-basic material.

\section{DESIGN OF ALTERNATORS FOR SWITCHGEAR TESTING}

A PAPER by V. Easton (J. Inst. Elec. Eng., 90, A Pt. 2, No. 16; August 1943) deals with some of the factors which affect alternator design. Due to the rapid growth of interconnexions on many systems during the last fifteen years, the greatly increased voltage and current likely to be caused by a fault at many switching stations has necessitated the design of circuit-breakers of larger capacity, and in turn this has made desirable improved facilities for technical investigations and for proving the rating of the breakers. The paper discusses the mechanical and electrical factors which affect the design of alternators supplying power for switchgear testing, and a review is made of several methods of increasing the output of such alternators, the merits of each being critically examined.

In the section on electrical design the author deals with reactance, time-constants and damping circuits, recovery voltage, and speed of plant and losses. The section on mechanical design covers slot conductors, end windings, foundations and couplings. Finally, the author discusses various methods of increasing output and considers the effect of external reactance, increased initial voltage, shorter duration of test, super-excitation, and parallel operation of plant. All the methods to increase output may be applied to. existing plant, the most suitable probably being an increase in the initial voltage or a reduction in the duration of the test period. Super-excitation may also be adopted, but if complete neutralization of the stator M.M.F. is desired the super-exciter set must be of large capacity, probably designed for a high voltage, and the arrangement may be relatively inelficient.

The method to be adopted for an extension to existing plant may be influenced by the arrangement of the sets with which it is required to run in parallel, but for a new installation some degree of super-excitation should be provided. The choice lies between a large excitation set capable of maintaining the stator current at the initial value and a small set with controlled switching to eliminate the D.C. component of the stator current and permit the switch under test to be opened a few cycles after the master switch closes. Technically, the former scheme is the more satisfactory from the point of view of the flexibility of the testing procedure, the severity of the test conditions, and ease in interpreting the results. Economic considerations may, however, bo of sufficient importance to offset the complications and the reduction in the severity of the test introduced by controlled switching.

\section{RIVER CONTROL IN BRITAIN}

A MONG the terms of reference of the Central A Advisory Water Committee was a consideration of what enactments, if any, were required to co-ordinate the various river interests, and the desirability of constituting new river authorities with responsibility for some or all of the functions now exercised by existing bodies. There were found*, on examination of the subject, a great many bodies each exercising limited control generally of one or

* Ministry of Health. Third Report of the Central Advisory Water Committee: River Boards. (Cmd. 6465.) Pp. 77. (London: H.M. Stationery Office, 1943.) 18. 3d. net. 